\title{
A comparative analysis between laser machine \& hand scrapping for inducing destroy effect on denim garment
}

\author{
Abir Khan \\ Textile Engineering Department, National Institute of Textile Engineering and Research \\ DOI: 10.29322/IJSRP.10.03.2020.p9937 \\ http://dx.doi.org/10.29322/IJSRP.10.03.2020.p9937
}

\begin{abstract}
The aim of this study was to assess the destroyed effect on denim garment by laser machine and by conventional hand scrapping technique. A local washing plant was used as the facility to prepare samples for both laser machine and hand scrapping. The result of this study gives us an understanding of the both procedures as well as comparison of the induced effect by both techniques. This study recommends the use of laser wash technique over manual hand scrapping technique as the former yields better design effect with user friendliness. Also the laser machine is more sustainable than manual hand scrapping technique.
\end{abstract}

Index Terms- Denim dry wash, Destroy effect, Hand scrapping, Laser wash.

\section{INTRODUCTION}

$\mathrm{D}$ enim is considered one of the most popular clothing among people of all ages and gender. The aesthetic appeal of denim surpasses any other clothing. Denim is a hard and durable ward faced 3/1 twill cotton fabric, woven with indigo dyed ward and white filling yarns, having weights of 14.5 ounces per square yard (R. Paul; Denim: Manufacture, Finishing and Application). Due to enhanced durability denim has been used for centuries especially by people of hard labor. But now it is not only considered a work wear but also fashionable apparel. As denim had been worn by people of hard labor after a prolonged time of day to day activities the garment used to become faded. This faded and worn out look has now become a trend. But in order to induce the faded look various wash techniques have been developed. The scope of denim wash process is very broad. Innovative denim products will be able to open up new markets and horizons for denim industry. Customers today have a wide range of choices and the one who produces the best quality at a high competitive will survive and prosper. Innovative and enhanced results are possible through application of various types of denim wash processes, which in turn would bring greater financial profits. When a wash technique is selected; sustainability of the process must be assessed because denim industry uses a large amount of water and chemicals.

\section{Denim Washing TeChNiQues}

Denim garments can be washed in two ways: i) Dry process and ii) Wet process. The wash processes are ways to achieve color fading, enhanced handle property and unique looks. Dry process includes techniques that don't require use of chemicals and water whereas wet process involves use of various chemicals and large amount of water. Since sustainability has become a concern worldwide dry process or nearly water free techniques are becoming popular and recommended. Among the various dry wash techniques laser wash and hand scrapping are notable ones.

\section{Laser wash technique}

Application of laser in textile products dates back to the late 1990's. The laser beam induces various effects on garments. The energy provided by a laser beam has two effects on indigo dyed fabrics (Bosman, 2007). Laser beam does two operations on denim garment: it sublimates the indigo dye stuff and burns the colored yard revealing the undyed yarns.

\section{Hand scrapping technique}

This is a manual technique followed to impart worn out look on denim garments. In this process the area to be faded is identified at first and then a piece of emery paper is rubbed on the selected area to rub off the surface color. Precise control of hand movement is very crucial in this process otherwise regularity of the faded design might not be achieved. So skilled and experienced workers are required for this process. 


\section{Methodology}

In order to carry out laser and hand scrapping technique two samples (100\% cotton) of similar fabric construction ( $3 / 1 \mathrm{Z}$ twill) and weight (14oz/yard) has been collected from local markets. Regular design effect has been taken. The washing processes have been carried out in a local washing factory named "Qupid Washing". For laser wash following machine has been used:

\begin{tabular}{|l|l|}
\hline \multicolumn{1}{|c|}{ Brand Name } & \multicolumn{1}{c|}{ ARGES Laser System } \\
\hline Origin & Turkey \\
\hline Laser Type & $\mathrm{CO}_{2} \mathrm{RF}$ metal laser \\
\hline Laser Power & $12 \mathrm{KW}$ \\
\hline Working Area & $1500 \times 3000 \mathrm{~mm}$ \\
\hline Working Table & Conveyor mesh belt \\
\hline Processing Speed & Adjustable \\
\hline Positioning accuracy & $\pm 0.1 \mathrm{~mm}$ \\
\hline Motion System & Offline mode servo motor control system,5" LCD screen \\
\hline Cooling System & Constant temperature water chiller \\
\hline Power supply & 380 v 50 Hz 3 P N PE \\
\hline Design Format Support & AJ, BMP, PLT, DXF, DST et \\
\hline Standard collection & Projection system, integrated working table, auxiliary ladder, fixed top exhaust suction system \\
\hline Working Room Temperature & Less than 60 ${ }^{\circ} \mathrm{c}$ \\
\hline Drivers & Panasonic Servo drivers \\
\hline
\end{tabular}

\section{Reasons for choosing ARGES Laser System:}

I. Simple processing

II. Low sample rejection rate

III. Environment friendly

IV. Wide range of application

For hand scrapping process 400 number emery paper has been used.

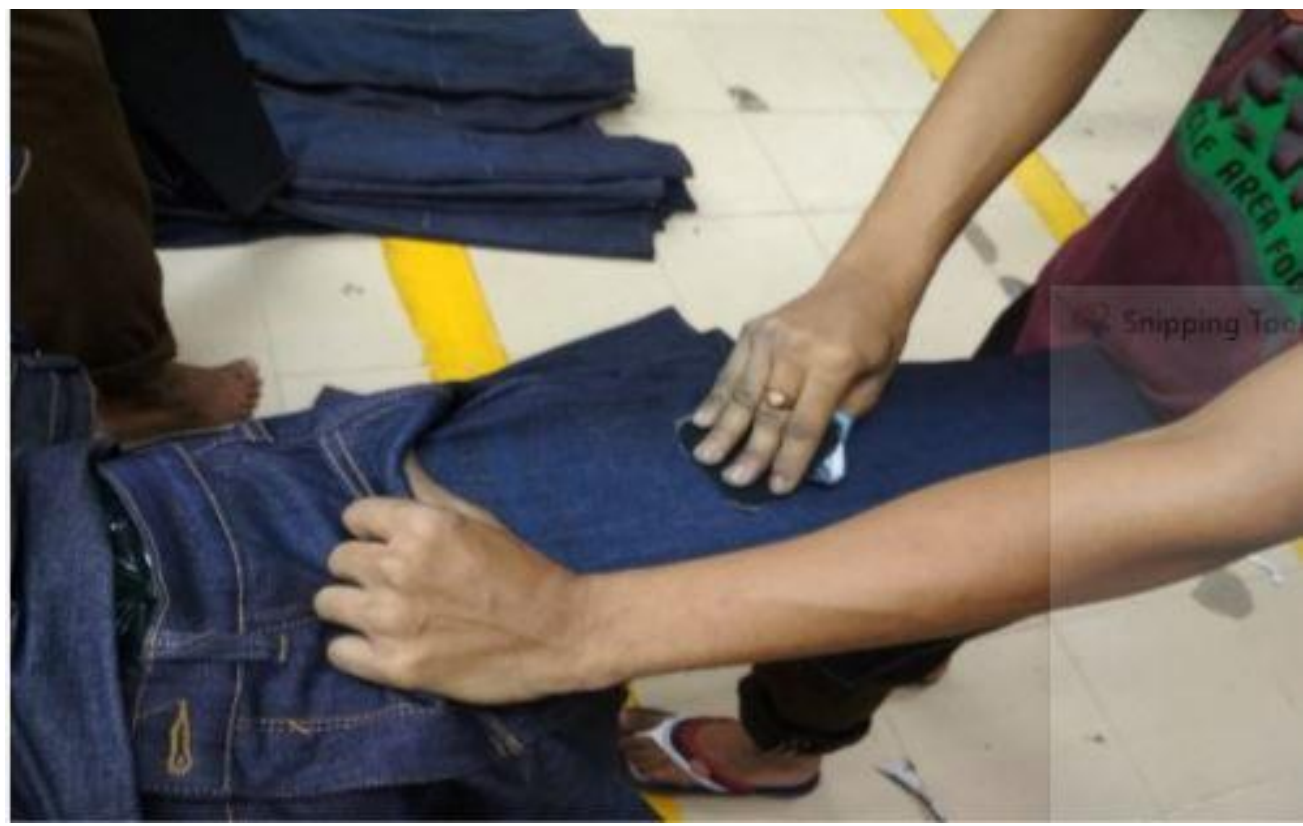

Fig 1: Hand Scrapping technique 


\section{RESULT \& ANALYSIS}

\section{Design outlook}

Laser machine produced a uniform design whereas the manual hand scrapping technique couldn't maintain uniformity.

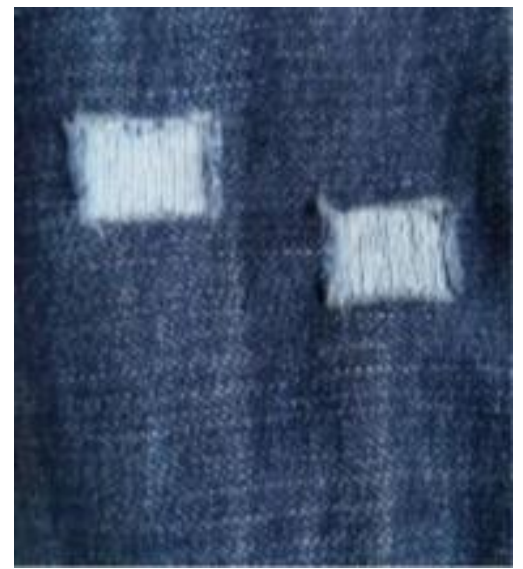

Fig 2: Destroy effect by Laser

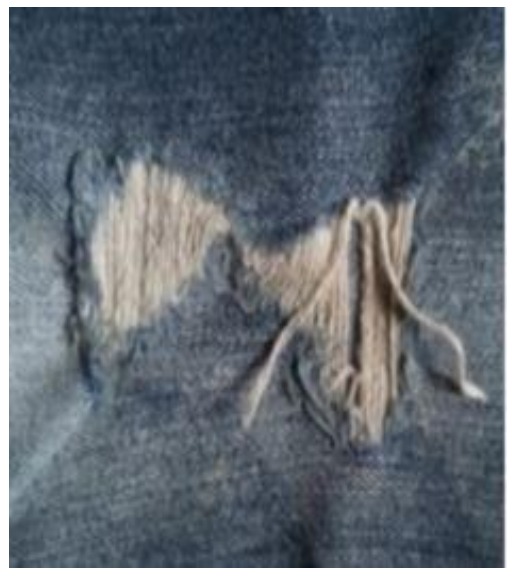

Fig 3: Destroy effect by Hand Scrapping

\section{Advantages of Laser wash technique over hand scrapping}

I. Any design at any place can be created. Fading on seams, on metal buttons is possible.

II. Faster process compared to the conventional processes.

III. Suitable for wide range of material.

IV. Comparatively less strength loss than other mechanical fading.

V. Low hairiness compared to other mechanical fading.

VI. Environment friendly.

VII. Zero water waste.

VIII. Requires no chemical.

IX. Less manpower required.

X. Rejection rate is 0\% in Laser system whereas around 5\% in Manual system.

\section{CONCLUSION}

This study showed that the laser system can provide a better design effect with comparatively less processing time and almost zero sample rejection rate. Also on sustainability front the laser machine is clearly ahead of manual technique. Although the initial investment cost for laser machine is much higher than manual processing techniques; the end result will be better than manual techniques. So this study suggests that for dry process on denim the use of laser machine is more favorable than manual hand scrapping technique.

\section{REFERENCES}

[1] Denim: Manufacture, Finishing and Applications edited by Roshan Paul

[2] "Garments Merchandising" by Prof. M.A. Kashem.

[3] http://www.fibre2fashion.com/industry-article/38/3762/denim-dry-finishing1.as

[4] http://learnapparel.blogspot.com/2013/02/dry-process-on-denim-part-1.html

[5] http://learnapparel.blogspot.com/2013/02/dry-process-on-denim-part-2.html

[6] http://www.indiantextilejournal.com/articles/FAdetails.asp?id=4330

[7] https://www.argeslaser.cc/jeans-denim-laser-engraving-laser-washingmachine.html

\section{AUTHORS}

First Author - Abir Khan, Lecturer, National Institute of Textile Engineering and Research, abirkhan03@ gmail.com. 